\title{
Gingival Epulis: Report of Two Cases.
}

\author{
Dr. Praful Choudhari ${ }^{1}$, Dr. Praneeta Kamble ${ }^{2}$, Dr.Aankasha Jadhav ${ }^{3}$ \\ 1- Sr. Lecturer, Dept. of Periodontology, Chattisgarh Dental College and Research Institute,Rajnandgaon.State- \\ Chattisgarh, India. 2-Associate Professor, Dept. of Periodontology,Nair Hospital Dental College, Mumbai, \\ Maharashtra State, India. 3- Post graduate student, Dept. of Periodontology,Nair Hospital Dental College,
} Mumbai, Maharashtra State, India,

\begin{abstract}
The word epulis is a clinical term used to describe a localized growth on the gingiva. Histologic examination of epulides indicates that the vast majority are the fibrous hyperplasias, peripheral ossifying fibomas, pyogenic granulomas or peripheral giant cell granulomas. The major epulides are common oral lesions with which dentists should be thoroughly familiar. The clinical and histological relevance of the two cases are discussed and analyzed for their biological behaviour.
\end{abstract}

Key Words: Epulis, Peripheral Giant Cell Granuloma, Giant Cell Epullis, Reparative Giant Cell Granuloma, Giant Cell Granuloma.

\section{Introduction}

Epulis is a nonspecific term applied to tumors and tumor like masses of the gingiva. Specifically, it is a term used to describe subepithelial tumifications of the gingiva or alveolar mucosa, with or without ulceration. Therefore, lesions occurring on the gingiva but exhibiting distinct epithelial changes, such as verruca vulgaris, papilloma and primary squamous cell carcinoma are not epulides. On the other hand, odontogenic tumors such as the peripheral ameloblastoma and odontogenic cysts such as the gingival cyst of the adult occur on the gingiva and appear clinically as epulides. Benign connective tissue neoplasms such as neurofibromas and leiomyomas may occasionally present as epulides. Malignant epulides are rarely encountered. Primarily, however epulides represent reactive hyperplasias of connective tissue cells of gingiva or superficial periodontal ligament. These common epulides are fibrous hyperplasia, peripheral ossifying fibroma, pyogenic granuloma and peripheral giant cell granuloma. This paper reviews the clinical and histological features of 2 cases of epulis patients with same location (anterior mandibular region) and age group (18 - 19 years).

\subsection{CASE 1}

\section{Case Presentation}

A 18 year female patient came to the OPD of Periodontics, Nair Hospital Dental College, Mumbai with swelling in lower front gums since 6 month, increased since its onset causing displacement of the front teeth and creating a space between them. The swelling has been present since approx. 6 months .The swelling is painless, and has gradually grown to its present size. There was no history of associated pain with the swelling. History of Bleeding from the gums in the area during tooth brushing. Intraoral examination revealed reddish-pink, well defined, firm, nonfluctuant swelling of $2 \times 1 \mathrm{cms}$ and extending from labio-lingually with a sessile base in relation to 31 to 41(Fig. 1, 2 ). Grade 1 mobile 31 and 41. The gingival and periodontal status of all teeth was good. Routine blood tests were within normal limits. Imaging with intraoral periapical radiograph revealed widening of periodontal ligament space, vertical bone loss in relation to 31, 41(Fig.3). Clinical diagnosis of generalized marginal gingivitis with gingival epulis in relation to 31 and 41 was made. Excisional biopsy was done (Fig.4) along with open flap debridement (Fig 5,6) as the patient was suffering from periodontitis. The growth was removed with an internal bevel incision (Fig. 7) and root surface was scaled and planed thoroughly. Periodontal pack and sutures was placed and the patient was recalled after 7 days for pack and suture removal. Microscopically (Fig.8), the lesion showed partially circumscribed tumor mass exhibiting interlacing fascicles of collagen fibers and areas of hemosiderin pigment. Intervening connective tissue also consisted of numerous localized areas of chronic inflammatory cells (mainly plasma cells). The overlying epithelium was hyperplastic, parakeratinized stratified squamous epithelium with thin, long rete ridges. The overall features were suggestive of fibrous hyperplasia with calcification. At follow-up, after a 1 month the wound healed satisfactorily (Fig .9, 10) 


\subsection{CASE 2}

A 18 year female patient came to the OPD of Periodontics, Nair Hospital Dental College, Mumbai with swelling in lower front gums since 6 month, increased since its onset, and had slowly grown to this size, Intraorally On examination, the swelling was approximately $0.8 \times 1 \mathrm{~cm}$ in size (Fig.1), was found to be sessile, lobulated, sharply demarcated but otherwise of the same color as the surrounding mucosa. On palpation, it had a fibrotic consistency. Complete full mouth periodontal examination revealed the presence of generalized chronic marginal gingivitis with epulis in relation to 31 and 41 regions. Intraoral periapical radiograph (Fig. 2) revealed interdental vertical bone loss in 31 and 41 region with widened periodontal ligament space. Blood investigations were not conclusive of any abnormality. Gingivectomy incision placed (Fig. 3) and the growth was removed (Fig.4, 5) and root surface was scaled and planed thoroughly. Periodontal pack was placed and the patient was recalled after 7 days for re-evaluation and pack removal. Microscopically (Fig. 6), fibrovascular connective tissue stroma with numerous collagen fibers, plump fibroblasts, numerous large multinucleated giant cells \& numerous capillaries with foci of hemorrhage \& hemosiderin pigments were seen. A diagnosis of Peripheral Giant Cell Granuloma was then made. At follow-up, after a week the wound healing was uneventful (Fig. 7)

\section{Discussion}

An epulis is a localized gingival growth, typically starting in the interdental papillae. The lesions which contain relatively little vascularity are focal fibrous hyperplasia and peripheral ossifying fibroma which are pink, smooth surfaced elevations that are usually asymptomatic. Those lesions which contain numerous vascular spaces (pyogenic granuloma and peripheral giant cell granuloma) are usually red smooth surfaced elevations and the degree of trauma to which they are subjected is often sufficient to cause focal ulceration and pain [1].

A possible hormonal (Estrogen \& progesteron) influence for some Peripheral Giant Cell Granuloma has been postulated by Whitaker [2] \& Giansanti [3]. Chambers discussing caillouette \& mattar's paper suggested that these hormones have immunosuppressive actions which contribute to growth of lesions [2]. In the present Case-1, this could also be one of the reasons, as the patient was female. Peripheral Giant Cell Granuloma shows a wide age distribution. Cooke [4] quoting Darlington's study \& others showed that majority of cases are between 4 - 6 decades. Brown, Darlington \& Kupfer [5] showed 37\% of lesions in range of 31 - 45 years of age, whereas Anderson [6] stated that it was found in younger patients. The present case-1 was 18 year old patient and case-2 was 19 year old.

Bhasker [7] \& Daley et al [1] have shown male predilection whereas several authors have noted a female predilection. Cases which are mentioned here were female and male patients. The histopathology reveals large number of multinucleated giant cells in vascularized fibrocellular stroma. In some cases the giant cells may be found in lumen of Capillaries. Hemorrhage, hemosiderin pigment, inflammatory cells \& newly formed bone or mature calcified material throughout the cellular stroma can be seen. Lesion may be covered by stratified squamous epithelium and ulcerated in some cases.In both cases the histopathological findings were corresponding to the above description [8].

The treatment is simple conservative excision of lesion with removal of any local source of irritation. Bhasker et al reported recurrence rate of $12 \%$, Katsikeris et al [9] reported $9.8 \%$ of recurrence rate and Anderson et al [6] on other hand reported a rate of 70.6\%. This would emphasize the importance of and follow up of such type of cases to know the recurrence rate.

\section{Conclusion}

Although the etiology was not exactly determined, abnormal habits, unfavourable oral hygiene and hormonal changes seemed to be predisposing factors in both cases. Since the etiology to cause epulis are multifactorial, it is not easy to determine the exact cause favouring the development of lesion. Clinically it is difficult to diagnose the lesion differentially with other closely resembling lesions like peripheral ossifying fibroma and fibroma. Hence a histopathological examination of the tissue specimen is mandatory for confirming the diagnosis. In conclusion, for treating such type of 
lesion, a complete surgical excision along with its base and elimination of irritating factors seems satisfactory to prevent further recurrence.

\section{References}

[1] Daley T.D., Wysocki G.P., Wysocki P.D. and Wysocki D.M.: The major epulides: Clinocopathological correlations. J Can Dent Assoc. 1990; 56(7):627-630.

[2] Whitaker S.R. and Bouquot J.E.: Identification of estrogen and progesterone receptors in peripheral giant cell lesions of the Jaws. $J$ Periodontol. 1994; 65(3):280-283.

[3] Giansanti J.S. and Waldron C.A.: Peripheral Giant Cell Granuloma: Review of 720 cases. J Oral Surg. 1969; $27: 787-791$.

[4] Cooke B.E.D.: The fibrous epulis and the fibroepithelial polyp: Their histogenesis and natural history. Br Dent J. 1952; 93:305309.

[5] Brown G.N., Darlington C.G. and Kupfer S.R.: A clinico-pathologic study of alveolar border epulis with special emphasis on benign giant cell tumor. Oral Surg. 1956; 9:765-775, 888-901.

[6] Anderson B.G.: Epulis. A series of cases. Arch Surg. 1939; 38:1030-1039.

[7] Bhasker S.N., Duane E., Beasley J.D. and Perez B.: Giant cell reparative granuloma (Peripheral): Report of 50 cases. J Oral Surg. $1971 ; 29: 110-115$.

[8] Neville B.W. et al., Oral and maxillofacial pathology (1st Ed. Philadelphia :W.B. Saunders Company, 1995).

[9] Katsikeris N., Kakarontza A. and Angelopoulos A.P.: Peripheral Giant Cell Granuloma. Clinicopathologic study of 224 new cases and review of 956 reported cases. Int J Oral Maxillofac Surg. 1988; 17:94-99.

\section{CASE 1.}

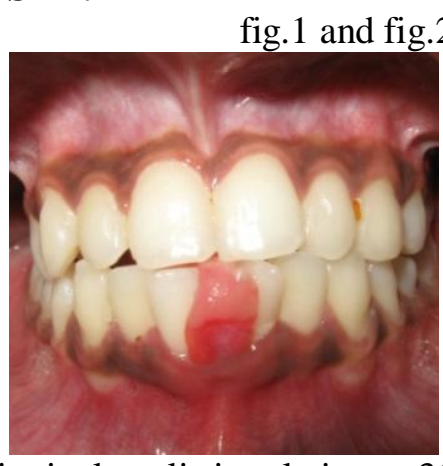

fig. 1 gingival epulis in relation to 31,41 , labial view

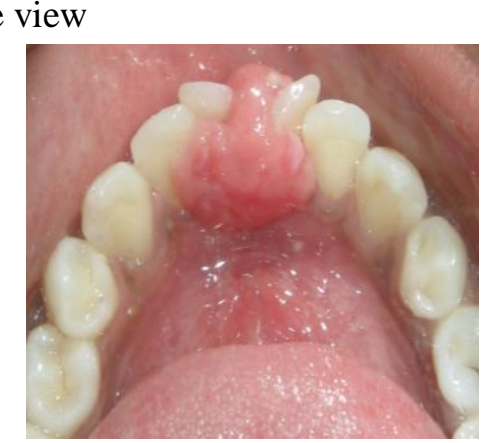

fig. 2 gingival epulis in relation to 3141 , lingual view

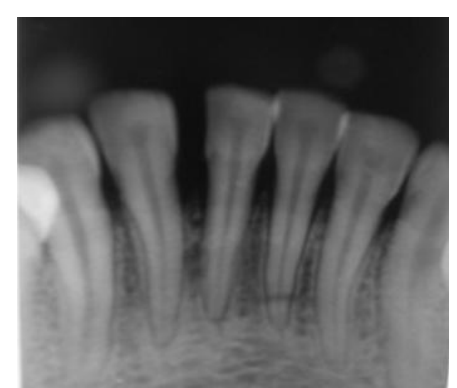

fig.3 intraoral periapical radiograph

fig. 4 and fig.5surgical view showing incision placement, excision of epulis and flap debridment

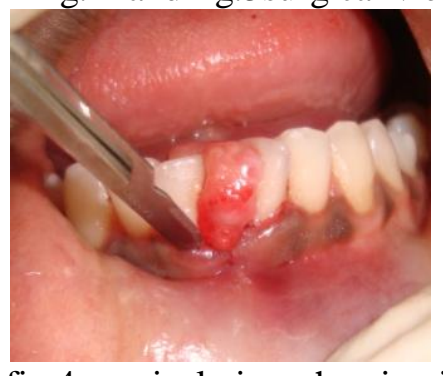

fig.4 surgical view showing incision

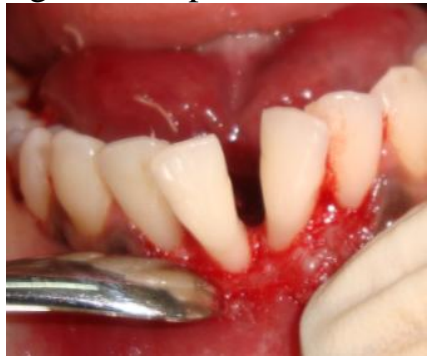

fig.5 excision of epulis

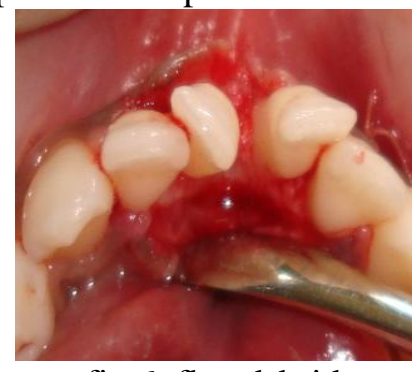

fig.6 flap debridment 
fig.7 and fig. 8 showing excised mass of tissue and histopathological examination

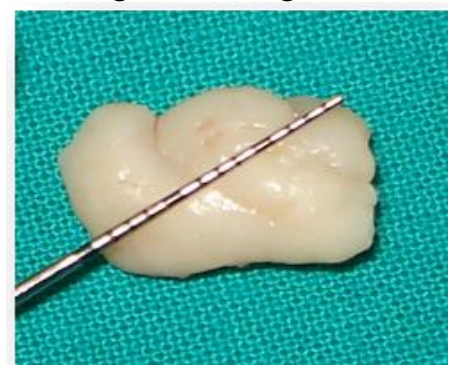

fig.7 excised mass of tissue

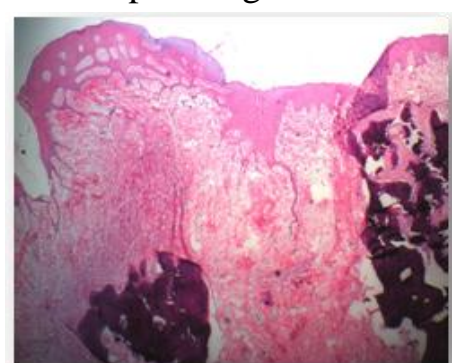

fig.8 histopathological view

Fig. 9 and 10 showing postoperative view after 1 month

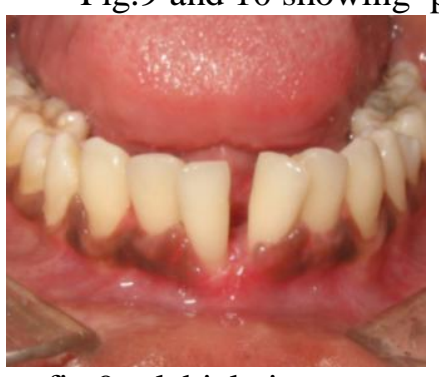

fig.9 labial view

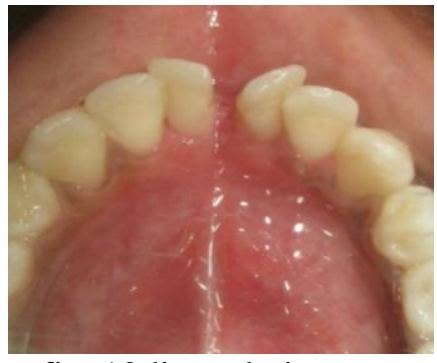

fig. 10 lingual view

\section{CASE 2}

fig. 1 and fig. 2 preoperative view with intraoral periapical radiograph

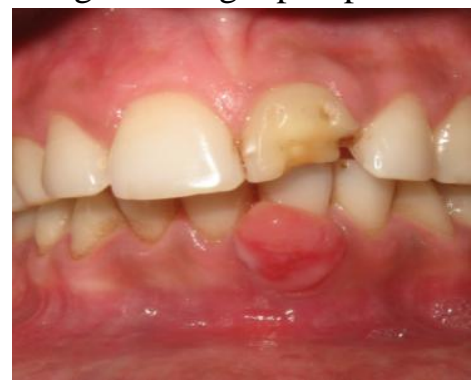

fig. 1 gingival epulis in relation to 31,41 ,

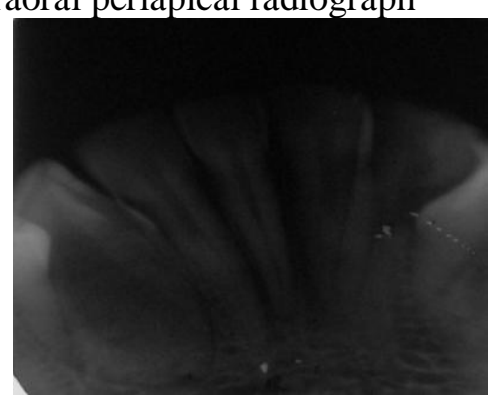

fig. 2 intraoral periapical radiograph

fig. 3 and fig. 4 surgical view showing incision placement, excision of epulis

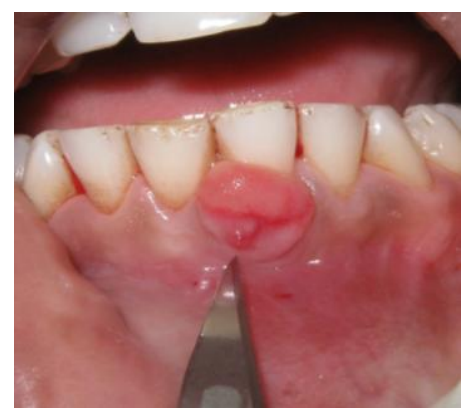

fig. 3 surgical view showing incision

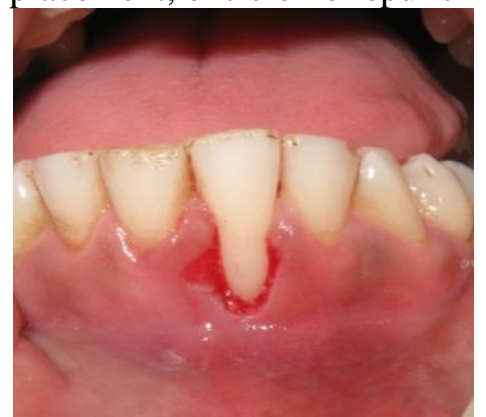

fig.4 excision of epulis 
fig 5 and fig.6 excised mass of tissue and histopathological examination

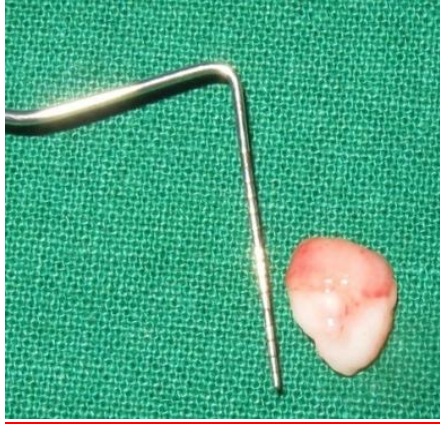

fig.5 excised mass of tissue

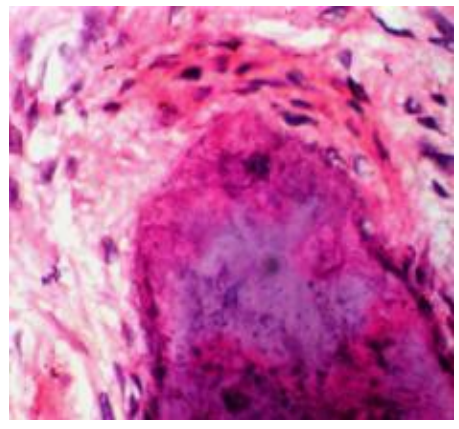

fig.6 histopathological view

Fig.7 postoperative view after 1 month

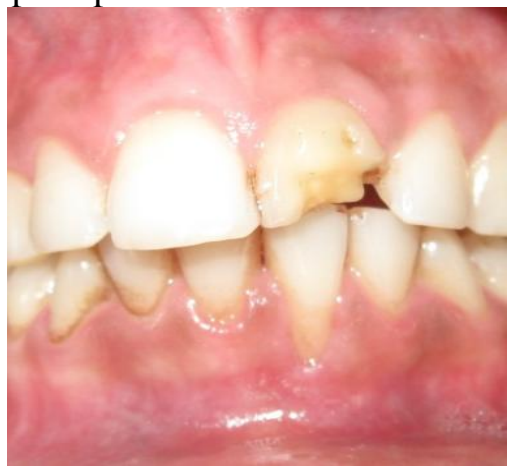

Fig.7 labial view 